\title{
Increased High Frequency Compared to Low Frequency Power in Heart Rate Variability in Parkinsonism
}

\author{
Rajani Bala Jasrotia ${ }^{1}$, Pramita Dubey ${ }^{1, *}$, Arvind Kanchan ${ }^{2}$, Nitin Ashok John ${ }^{1}$
}

\section{Rajani Bala Jasrotia', Pramita Dubey ${ }^{1, *}$, Arvind Kanchan², Nitin Ashok John ${ }^{1}$ 'Dr. Ram Manohar Lohia Institute of Medical Sciences, Gomti Nagar, Luc- know, Uttar Pradesh, INDIA. ${ }^{2}$ Hind Institute of Medical Sciences, Barabanki, Lucknow, Uttar Pradesh, INDIA.}

\section{*Correspondence}

\section{Pramita Dubey}

Dr. Ram Manohar Lohia Institute of Medical Sciences, Gomti Nagar-226010, Lucknow, Uttar Pradesh, INDIA.

Phone: +919454191974

Email: pramita3107@gmail.com

\section{History}

- Submission Date: 21-01-2021

- Review completed: 09-03-2021;

- Accepted Date: 27-03-2021.

DOI : 10.5530/ijcep.2021.8.1.9

Article Available online

http://www.ijcep.org

\section{Copyright}

(C) 2021 Phcog.Net. This is an openaccess article distributed under the terms of the Creative Commons Attribution 4.0 International license.

\begin{abstract}
Heart rate variability (HRV) decreases in Parkinson's disease which could be a consequence of reduced motor activity besides being a marker of cardiovascular dysautonomia. The diurnal low frequency power and high frequency power decrease in advanced Parkinsonism. In this case, there is decreased low frequency (LF) but high frequency (HF) is found to be very high compared to LF, which needs explanation. Multiple lobed pattern on Poincare plot in this case increases SD1, which has an analogy to HF, therefore HF is increased. If we remove premature beats from the recording while analysing, and then frame Poincare plot, it would be a normal torpedo pattern and HF value will be decreased in this case like LF, as is normally found in Parkinsonism, which would truly reflect the HRV values due to autonomic effects. HRV report should be interpreted for autonomic dysfunction when Poincare plot is torpedo pattern as other patterns may signify some intrinsic disease of heart.

Key words: Parkinsonism, Heart rate variability, High frequency, Multiple lobed poincaré plot, LF-HF ratio.
\end{abstract}

\section{INTRODUCTION}

Neurological disorders are the primary cause of disability, and there is increasing burden of neurodegenerative disorders, including Parkinson's disease (PD). ${ }^{[1]}$ Autonomic nervous system (ANS) dysfunction is common in PD, affecting $70 \%$ to $80 \%$ of patients, and causes significant morbidity and discomfort. ${ }^{[2]}$ Heart rate variability (HRV) has been studied in Parkinsonism and it was associated with disease severity. ${ }^{[3]}$ HRV decreases in PD which could only be a consequence of reduced motor activity besides being a marker of cardiovascular dysautonomia. The diurnal low frequency power and the ratio of low frequency (LF) and high frequency (HF) power decreased in advanced Parkinsonism with motor complications. The nocturnal vagal indicators such as HF power and pNN50 (the mean number of times an hour in which the change in successive normal sinus intervals exceeds $50 \mathrm{~ms}$ ) were found to be decreased in later stages. Despite higher motor activity due to dyskinesia, LF was low which suggested a defective cardiovascular upregulation. ${ }^{[4]}$ In this case report, there was decreased LF but HF was found to be very high compared to LF, which needs explanation.

\section{CASE REPORT}

This is a case of 55 year old male presented with pain in left arm while sleeping, for last 8-9 years, which was relieved on hot fomentation and on use of hard collar. Patient also complained of paresthesia in left

Cite this article: Jasrotia RB, Dubey $P$, Kanchan A, John NA. Increased High Frequency Compared to Low Frequency Power in Heart Rate Variability in Parkinsonism. Int J Clin Exp Physiol. 2021;8(1):35-7. 
alfa lipoic acid once a day. Autonomic function test (AFT) report is Table 1. Poincare plot is shown in Figure 1(a).

\section{DISCUSSION}

The prevalence of Parkinsonism was increasing globally. ${ }^{[1]}$ Its autonomic disability increased the morbidity which needs emphasis. Generally, decreased LF and HF was observed in Parkinsonism but in this case, HF was very high compared to LF, leading to very low LF-HF ratio. Poincare plot in this case is not a normal torpedo pattern but a multiple lobed pattern. ${ }^{[6]}$ This multiple lobed pattern increases SD1, which has an analogy to $\mathrm{HF}^{\left[{ }^{[7]}\right.}$ therefore $\mathrm{HF}$ was increased. These multiple lobes were due to premature atrial contractions ${ }^{[6]}$ in this case, which was also visible in electrocardiography while recording HRV. These premature atrial contractions were intrinsic abnormality of heart which alters the $\mathrm{HRV}^{[8]}$ If the premature beats [Figure $1(\mathrm{~b}, \mathrm{c})$ ] were removed from the recording while analysing, and then frame the Poincare plot, it would be a normal torpedo pattern and HF value will be decreased in this case like LF, as is normally found in Parkinsonism, which would truly reflected the HRV values due to autonomic effects. Then, other autonomic tests values (abnormal parasympathetic response) would be comparable with HRV values. Figures 1 (d, e) and Table 1 are showing how to remove premature contractions and the Poincaré plot and HRV values obtained after removing premature atrial contractions.

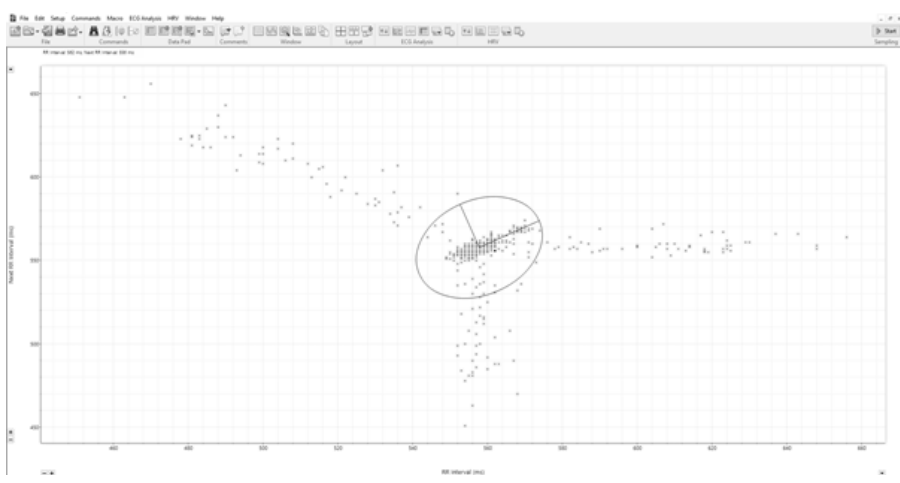

Figure 1(a): Poincaré plot: multiple lobed poincaré plot.

Multiple lobed poincaré plot was due to intrinsic defect of heart (i.e. premature atrial contractions). It does not purely reflect autonomic activity of cardiovascular system.

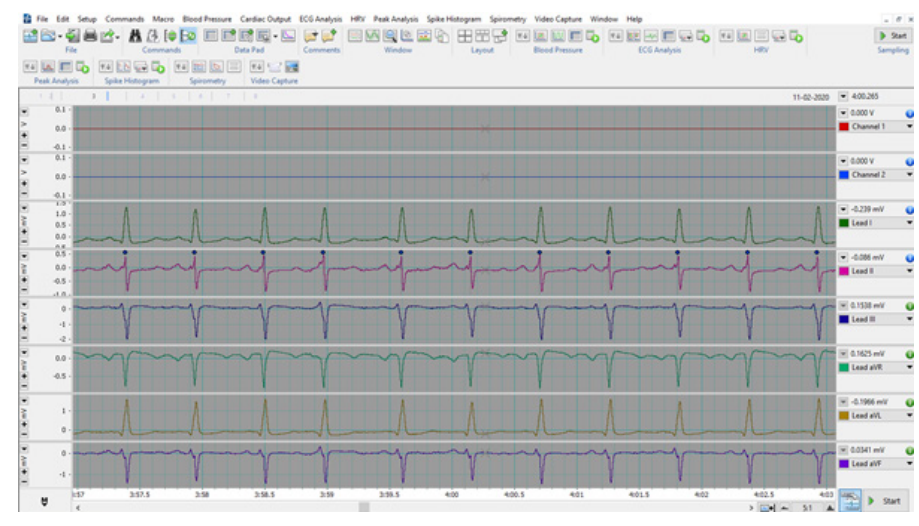

Figure 1(b): Premature atrial contraction at 3:59 picked (marked with blue dot like other beats) during HRV analysis resulted in multiple lobed Poincaré plot

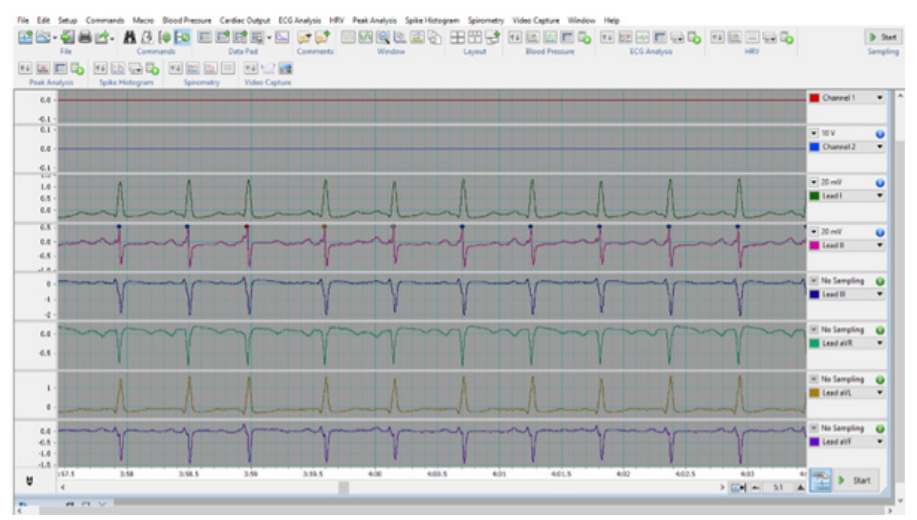

Figure 1(c): Premature atrial contraction at 3:59 not picked (marked with red dot together with 2 other consecutive beats marked yellow and grey) during HRV analysis resulting in torpedo pattern poincaré plot.

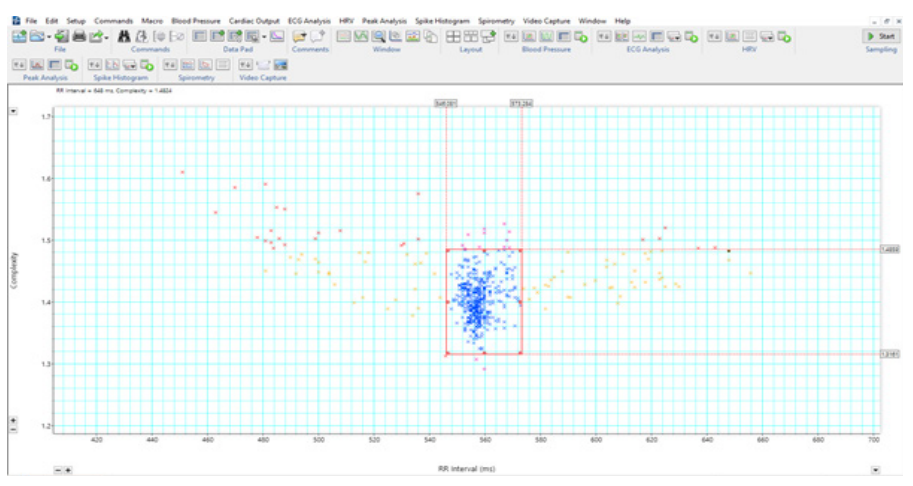

Figure 1(d): Figure showing how to remove premature atrial contractions. Selecting beats apart from premature atrial contraction beats, matched on HRV Electrocardiogram record.

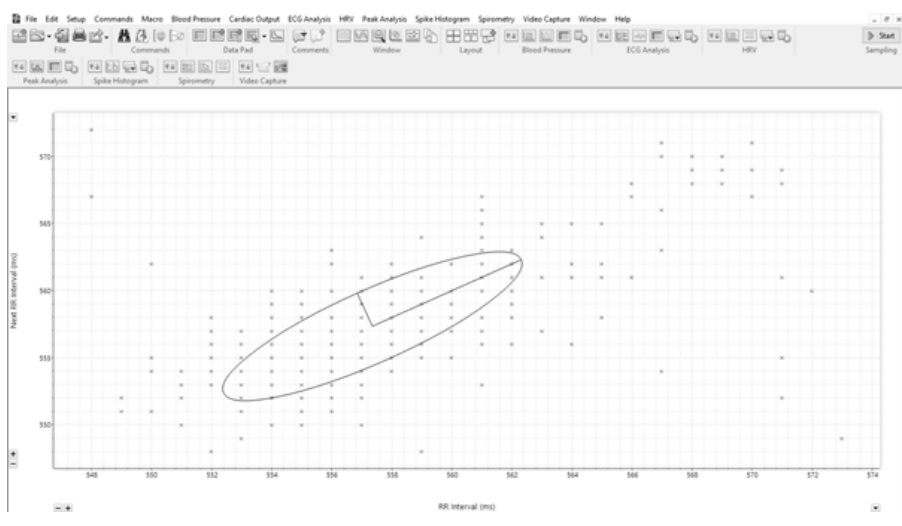

Figure 1(e): Torpedo pattern poincaré plot obtained after removing premature atrial contraction beats.

It now reflects ANS activity of cardiovascular system 
Table 1: AFT Report including HRV report before and after removing premature contractions.

\begin{tabular}{|c|c|}
\hline AFT parameter & Value \\
\hline $30: 15$ ratio & 0.992 (abnormal)[5] \\
\hline Deep breathing difference (DBD) & 10 (borderline) [5] \\
\hline Valsalva ratio & 0.9538 (abnormal)[5] \\
\hline $\begin{array}{l}\text { Diastolic blood pressure (DBP) } \\
\text { response to sustained handgrip }\end{array}$ & $5 \mathrm{~mm}$ mercury (abnormal) [5] \\
\hline Total power (before/after*) & 153 millisecond $2(\mathrm{~ms} 2) / 12.75 \mathrm{~ms} 2$ \\
\hline VLF (before/after ${ }^{*}$ ) & $5.355 \mathrm{~ms} 2 / 6.491 \mathrm{~ms} 2$ \\
\hline LF (before/after*) & $3.433 \mathrm{~ms} 2 / 2.648 \mathrm{~ms} 2$ \\
\hline HF (before/after ${ }^{\star}$ ) & $87.68 \mathrm{~ms} 2 / 3.397 \mathrm{~ms} 2$ \\
\hline LF/HF Ratio (before/after*) & $0.03916 / 0.7793$ \\
\hline $\begin{array}{c}\text { Standard deviation1 (SD1) (before/ } \\
\text { after }^{*} \text { ) }\end{array}$ & 26.9 millisecond $(\mathrm{ms}) / 2.706 \mathrm{~ms}$ \\
\hline $\begin{array}{c}\text { Standard deviation2 (SD2) (before/ } \\
\text { after }^{*} \text { ) }\end{array}$ & $16.64 \mathrm{~ms} / 5.441 \mathrm{~ms}$ \\
\hline
\end{tabular}

${ }^{*}$ Before/after: Before and after removing premature contractions

\section{CONCLUSION}

This study concluded that HRV report should be interpreted for autonomic dysfunction when Poincare plot is torpedo pattern as other patterns may signify some intrinsic disease of heart and not autonomic dysfunction. Premature atrial contraction beats can be removed while analysing HRV by changing settings to obtain a torpedo pattern. Then HRV will be a true reflection of autonomic dysfunction.

\section{ACKNOWLEDGEMENT}

We would like to acknowledge Dr. Shweta Gupta, Senior Resident form Department of Physiology, Dr. RMLIMS, Lucknow for proof reading the case report.

\section{CONFLICT OF INTEREST}

The authors declare no conflict of interest.

\section{ABBREVIATIONS}

ANS: Autonomic Nervous System; HRV: Heart Rate Variability; LF: Low Frequency; HF: High Frequency.

\section{REFERENCES}

1. Valery LF. Global, regional, and national burden of neurological disorders, 19902016: A systematic analysis for the global burden of disease study. Lancet Neurol. 2019;18(5):459-80

2. Zesiewicz TA, Baker MJ, Wahba M, Hauser RA. Autonomic nervous system dysfunction in parkinson's disease. Curr Treat Options Neurol. 2003;5(2):149-60.

3. Dorji H, Wen SH, Chen SY, HarnodT. The Association of heart rate variability with parkinsonian motor symptom duration. Yonsei Med J. 2014;55(5):1297-302

4. Devos D, Kroumova M, Bordet R, Vodougnon H, Guieu JD, Libersa C, et al. Heart rate variability and Parkinson's disease severity. J Neural Transm. 2003;110(9):997-1011.

5. Khandelwal E, Jaryal AK, Deepak KK. Pattern and prevalence of cardiovascular autonomic neuropathy in diabetics visiting a tertiary care referral center in India. Indian J Physiol Pharmacol. 2011;55(2):119-27.

6. Duong ND, Jeong $\mathrm{H}$, Youn $\mathrm{CH}$, Kim D. Development of new cluster descriptors for image analysis of Poincaré plots. InWorld Congress on Medical Physics and Biomedical Engineering, IFMBE Proceedings, vol 25/4. Munich, Germany: Springer, Berlin, Heidelberg. 2009;1661-4.

7. Shaffer F, Ginsberg JP. An overview of heart rate variability metrics and norms. Front Public Health. 2017;5:258. https://doi.org/10.3389/fpubh.2017.00258

8. Dubey P, Verma M, John NA, Gutch M. Nonlinear parameter of heart rate variability can diagnose early cardiac autonomic neuropathy. J Arrhythmia. 2020;36(3):534-6. https://doi.org/10.1002/joa3.12328

Cite this article: Jasrotia RB, Dubey P, Kanchan A, John NA. Increased High Frequency Compared to Low Frequency Power in Heart Rate Variability in Parkinsonism. Int J Clin Exp Physiol. 2021;8(1):35-7. 